\title{
OR-44
}

\section{The Identification of Isomers of Pandanus Alkaloids}

\author{
Ummu Amirah Armayni*, Mohd Sharil Bin Ahmad, Nuruljannah Bt Md Yusof, Hannis Fadzillah \\ Mohsin and Ibtisam Abdul Wahab \\ Faculty of Pharmacy, Universiti Teknologi MARA, 42300 Puncak Alam, Selangor, Malaysia; \\ E-mail: amirahummu@yahoo.com
}

The occurrence of alkaloids in Pandanaceae family was studied, due to their structural distinctiveness. Within the Pandanus genus, the alkaloidal components were investigated from $P$. amaryllifolius (the scented screwpines), followed by $P$. dubius (locally known as mengkuang). Pandanus' aromatic compound is attributed to a simple alkaloid, 2-acetyl-1-pyrroline. To date, twenty two alkaloids were reported from the above species, out of 600 Pandanus plants. From the review, it is anticipated that a specific Pandanus would contain a particular alkaloidal skeleton. The carbon arrangement might be constructed owing to the enzymatic cyclisation of the biogenetic precursor, Pandanamine. Hence, it is factual that Pygmauesamine, which possess an indolizidine, is a new alkaloid from P. pygmaeus. However, following a repetitive extraction of the leaves, another molecule could be purified. Based on the spectroscopic data, it is aimed that an isomer of Pygmauesamine could be recognized. The methodology includes the gravitational silica column and centrifugal radial thin layer chromatography of the dichloromethane extract. Nuclear magnetic resonance (NMR) spectroscopy $\left(500 \mathrm{MHz}, \mathrm{CDCl}_{3}, \delta_{\mathrm{H}} 0-8 \mathrm{ppm}\right)$ was used to identify the molecular structures. The findings include the isolation of one alkaloid. An orange spot was observed when the silica plate was sprayed with the Dragendorff reagent. Spectroscopic evidences suggested that the protons' chemical shifts of this molecule are assortment of signals from Pandanamine (an alkaloid from P. amaryllifolius) and Dubiusamine A (a biologically active alkaloid from $P$. dubius). The presence of additional protons in the structure might give a molecular formula of $\mathrm{C}_{18} \mathrm{H}_{27} \mathrm{NO}_{4}$. Consequently, an isomeric Pygmaeusamine, arbitrarily labeled as Pygmaeusamine B, was proposed as another alkaloid from $P$. pygmaeus. The NMR spectral elucidation of this compound could suggest that it is a novel Pandanus alkaloid. Subsequent assessments will also feature the protons' spatial interaction in Pygmaeusamine B and the confirmation of the mass data.

Keywords: Alkaloids, Pandanus. 